\title{
Goal-driven modulation of stimulus-driven attentional capture in multiple-cue displays
}

\author{
CHRISTIAN M. RICHARD \\ University of British Columbia, Vancouver, British Columbia, Canada \\ RICHARD D. WRIGHT \\ Simon Fraser University, Burnaby, British Columbia, Canada \\ and \\ LAWRENCE M. WARD \\ University of British Columbia, Vancouver, British Columbia, Canada
}

\begin{abstract}
Six location-cuing experiments were conducted to examine the goal-driven control of attentional capture in multiple-cue displays. In most of the experiments, the cue display consisted of the simultaneous presentation of a red direct cue that was highly predictive of the target location (the unique cue) and three gray direct cues (the standard cues) that were not predictive of the location. The results indicated that although target responses were faster at all cued locations relative to uncued locations, they were significantly faster at the unique-cue location than at the standard-cue locations. Other results suggest that the faster responses produced by direct cues may be associated with two different components: an attention-related component that can be modulated by goal-driven factors and a nonattentional component that occurs in parallel at multiple direct-cue locations and is minimally affected by the same goal-driven factors.
\end{abstract}

Whether it is during a drive to work or while walking in a crowded market, humans are often faced with complex and dynamic visual environments. Successful interactions in these situations often involve dealing with information that appears suddenly in the visual scene. Sometimes this information requires immediate action, as when a distracted driver cuts carelessly into your lane on the road ahead. At other times, no action is required, as when a business sign on the side of the road lights up. In order to function efficiently in these environments, it is important to be able to rapidly distinguish between different types of stimuli.

One of the ways in which humans can determine whether or not visual information requires an immediate response is to pay attention to it. Visual attention has been described as an information-processing focus that facilitates the detection or identification of visual stimuli at the location with which it is aligned (e.g., Posner, 1980). Visual attention is typically said to occupy a single contiguous region of space, thereby restricting the processing of visual information to one area at a time (e.g., Eriksen \& Yeh, 1985; Heinze et al., 1994; Kiefer \& Siple, 1987;

This work was supported by grants from the Natural Sciences and Engineering Research Council of Canada (NSERC). We thank John McDonald for useful discussions and Godwin Chan for research assistance. We also thank Jeremy Wolfe, Marylou Cheal, and two anonymous reviewers for their valuable comments. Correspondence concerning this article should be addressed to L. M. Ward, Department of Psychology, University of British Columbia, 2136 West Mall, Vancouver, BC, V6T 1Z4 Canada (e-mail: lward@ cortex.psych.ubc.ca).
McCormick \& Klein, 1990; Posner, Snyder, \& Davidson, 1980; however, see Kramer \& Hahn, 1995). In other words, if some region receives attention, it is to the exclusion of other locations. This limitation necessitates selective control over the position of attention in visual space.

If certain visual information requires attention, observers can voluntarily shift their attention to the location of that information in a goal-driven manner (see Table 1). This type of attention shift is based on top-down operations and requires active involvement on the part of the observer. An example is the attention shift that often occurs when people perform spatial-cuing experiments. In this case, a symbolic cue (e.g., an arrow; also known as a central cue) appears within the visual scene, indicating a potential onset location of a subsequent target to be detected. Observers can use the location information conveyed by the cue to voluntarily shift their attention to the indicated location in advance of the target onset. This typically results in faster and more accurate responses to the target if it appears at the cued location, as opposed to an uncued location (e.g., Posner et al., 1980). When describing the results of the experiments in this paper, we will refer to the difference between responses to targets at cued locations and responses to targets at uncued locations as the cue effect.

Top-down intervention is not always required for focusing attention on visual information. If a stimulus appears abruptly in the visual scene, then, under certain conditions, that stimulus can involuntarily draw attention to its location in a stimulus-driven manner (also referred 
Table 1

Two Means by Which Control Over Visual Attention Shifts Can Be Exercised by Location Cuing

Stimulus-Driven Attention Control

Associated with direct cues (a.k.a. peripheral or exogenous cues) that occur directly at a potential target location

Initiated by sensory event, such as the abrupt onset of a direct cue or other transients

Effects are rapid and transient, peaking approximately $100 \mathrm{msec}$ after a cue onset

Are involuntary because they are minimally influenced by (1) instructions to ignore the cues or (2) the predictability (validity) of the cues
Goal-Driven Attention Control

Associated with symbolic cues (a.k.a. central or endogenous cues) that indirectly indicate a potential target location

Initiated by cognitive operations, usually following the interpretation of a symbolic cue's meaning

Effects are more gradual and sustained, peaking approximately $300 \mathrm{msec}$ after the cue onset

Are voluntary because they are diminished (1) by instructions to ignore the cues or (2) if the cue is not useful to the subject (e.g., low cue predictability) to as attentional capture; see Table 1). Stimulus-driven attention shifts can be initiated by direct cues (also known as peripheral cues). These cues take the form of abrupt luminance changes (e.g., the onset of a bar marker) that occur before the target appears. As is the case with symbolic cuing, if a subsequent target is then presented at a direct-cue location, it is also typically processed faster and more accurately than if it had been presented at an uncued location (e.g., Posner, 1980).

Stimulus-driven and goal-driven attention shifts exhibit different properties. One of the ways in which they differ is the time course of symbolic-cue and direct-cue effectiveness. This can be measured by varying cue-target onset asynchrony (CTOA), which is the time interval between the onset of a cue and the onset of the target. The results of several studies indicate that goal-driven attention shifts are associated with cue effects that are sustained over time, lasting up to several seconds (e.g., Cheal \& Lyon, 1991; Müller \& Findlay, 1988; Müller \& Rabbitt, 1989). In contrast, the effects of direct cues that trigger stimulus-driven attention shifts are usually transient, peaking quickly around $100 \mathrm{msec}$ after onset and dropping back to baseline thereafter if observers have no incentive to maintain their attention at the cued location (Müller \& Rabbitt, 1989; Nakayama \& Mackeben, 1989; Weichselgartner \& Sperling, 1987).

Stimulus-driven and goal-driven attention shifts are also differentially affected by cue validity. Cue validity is a measure of the probability that the target will appear at a cued location. A cue's validity can range from low, if it does not indicate the target's actual location at a better than chance level, to high, if the cue indicates the correct target location on most trials. The results of some studies indicate that stimulus-driven attention shifts occur when cue validity is either high or low, whereas goal-driven attention shifts seem to occur only when cue validity is high (Jonides, 1981; Weichselgartner \& Sperling, 1987), unless observers are given specific instructions to attend to the cued locations (e.g., Gottlob, Cheal, \& Lyon, 1999; Jonides, 1981).

In summary, at least two different processes are involved in controlling the allocation of attention in visual space (see, also, Egeth \& Yantis, 1997; Wright \& Ward,
1998; Yantis, 1998). One process requires the involvement of goal-driven operations that are associated with certain conditions, such as high cue validity or instructions, that provide the necessary incentive for observers to actively shift attention. And once attention is shifted to a location, it can be sustained there for an additional period of time if the observer chooses to do so. In contrast, a second process involves stimulus-driven operations that trigger attention shifts without the observer's active involvement. These shifts occur quickly and involuntarily but have only a transient effect on subsequent attentional processing unless additional incentives to maintain attention at the cued location are provided.

\section{Stimulus-Driven Attentional Capture}

The processes mediating stimulus-driven attention shifts involve a simple causal relationship between an abrupt stimulus onset and attention. More specifically, if a single stimulus appears abruptly in the visual scene, it will, in most cases, involuntarily trigger an attention shift to its location (e.g., Jonides \& Yantis, 1988; Yantis \& Jonides, 1984). Although this may account for the results of many spatial-cuing studies employing only a single direct cue, it may not adequately explain other findings, such as those obtained when multiple stimuli appear abruptly at several locations at the same time. Presumably, when the latter occurs, several different stimulus onset signals compete for the same attentional focus. This leads to questions such as the following: How is just one of the signals selected for attentional capture, and, when this occurs, how are the other unattended stimulus onset signals processed?

These questions have been addressed by positing that stimulus-driven orienting involves an early stage of processing during which abrupt-onset stimuli are initially coded by a preattentive abrupt-onset prioritization mechanism (e.g., Yantis \& Jones, 1991). This mechanism assigns temporally decaying priority tags to the locations of all abrupt-onset stimuli. Attention is then said to be allocated to different locations in a sequence determined by the order of the strongest priority signals (with each priority signal being reset to null once its location has been attended to). Thus, while a single abrupt-onset 
stimulus may capture attention directly, multiple abruptonset stimuli are said to capture attention serially until all locations have been attended to or until the signal strength of the remaining priority tags decays to a baseline level.

Much of the evidence for this proposal comes from visual search experiments in which the display items appear either gradually (no-onset items) or with an abrupt onset (e.g., Yantis \& Jonides, 1984). Targets are found faster if they have an abrupt onset, as opposed to a gradual onset. This holds true even for multiple abrupt-onset stimuli (Yantis \& Johnson, 1990; Yantis \& Jones, 1991). In this case, up to four such stimuli appear to receive priority access to visual attention before any of the no-onset stimuli are given access. Furthermore, the number of abrupt-onset stimuli processed with a high priority appears to decrease if the time required to inspect each stimulus item is increased (e.g., by adding noise to the display; Yantis \& Jones, 1991). The latter result supports the claim that there is a limit to how long the priority signals last, because if it takes longer to search for individual stimulus items, fewer higher priority abrupt-onset stimuli can be inspected before their priority advantage decays to baseline.

Note that in these studies, the target was no more likely to be an abrupt-onset item than a no-onset item. Therefore, subjects had no a priori incentive to strategically attend to abrupt-onset items in a goal-driven manner in order to maximize the probability that they would be focusing at a target location. This suggests that attentional capture by abrupt-onset stimuli can be mediated entirely by stimulus-driven processes (e.g., Yantis \& Jonides, 1984).

Whereas the priority-tagging model holds that the abrupt-onset processing advantage is mediated by a mechanism that controls attention in a sequential manner, an alternative position holds that this processing advantage can be mediated by operations that occur in parallel across the visual scene. According to this view, sensory activity generated by an abrupt-onset stimulus produces location-specific processing facilitation that is independent of focused attention (e.g., Tassinari, Aglioti, Chelazzi, Peru, \& Berlucchi, 1994; Tepin \& Dark, 1992; Wright, 1994; Wright \& Richard, 2003). In this case, sensory activity might initiate operations that either speed or facilitate the processing of information that occurs at that location (perhaps by "revving up" processing to provide a "head start" relative to processing at other locations) or by speeding up the opening of an attention channel at those locations (e.g., LaBerge \& Brown, 1989). This nonattentional processing could be triggered by sensory-related neural activity generated by external luminance transients in several brain areas (e.g., Kastner \& Ungerleider, 2000).

As has been suggested elsewhere (e.g., Theeuwes, Kramer, \& Atchley, 1998; Watson \& Humphreys, 1997; Wright \& Richard, 1998), there is a difference between tagging a location (sometimes referred to as visual marking) and the sensory consequences of direct cuing. Tag- ging, or marking, is related more to the order of priority of attentional selection of objects than to the initiation of sensory processing. Watson and Humphreys (1997) suggested that marking facilitates visual search by enabling the locations of previously inspected objects to be inhibited (see Posner \& Cohen, 1984). We have also developed this idea elsewhere and have found that, unlike sensory-based effects on processing, marking is not always a reflexive consequence of stimulus onsets (Wright \& Richard, 1998, 2000). Moreover, in the present experiments, we found that the duration of sensory-based cue effects (about $100 \mathrm{msec}$ ) is significantly shorter than the duration of visual marking effects reported by Watson and Humphreys (1997), which is another indication that marking and the initiation of sensory processing are qualitatively different.

One version of the sensory-based explanation of processing facilitation holds that attention is captured when sensory activation at a given location surpasses a relative threshold (Wright \& Richard, 2003). In particular, if only a single abrupt-onset stimulus appears, its associated level of activation will surpass the threshold and allow that stimulus to capture attention. If more than one abrupt-onset stimulus appears at the same time, however, competition between them prevents the level of activation associated with any one stimulus from surpassing the threshold, and so none of the stimuli will capture attention. Nevertheless, attentional processing of a subsequent stimulus appearing at the location of a previous abrupt onset (e.g., a target appearing at a direct-cue location) may still be facilitated if the delay between their onsets is brief (e.g., $100 \mathrm{msec}$ or less), because the sensory activity generated by the initial abrupt onset decreases the time required to open an attention channel at that location (see LaBerge \& Brown, 1989). This is said to be the case because residual sensory activation at this location enables activation generated by a subsequent stimulus onset at that location to add to an activation base that is already closer to the attention threshold than would be the case for stimuli appearing at other, uncued locations. Furthermore, because such initial processing of stimuli is sensory based, facilitation of responses to targets is, in part, independent of later attentional processing of the stimuli.

The results of a recent direct-location-cuing study support this model (Wright \& Richard, 2003). On each trial, a variable number of direct cues (one, two, three, or four) was simultaneously presented $100 \mathrm{msec}$ before the target appeared. Target detection response times on singlecue trials showed a significant 35 -msec cue effect (difference between mean cued and uncued responses), indicating that the cue captured attention on these trials. On the multiple-cue trials (two to four cues), cue effects were smaller $(18-19 \mathrm{msec})$ and did not differ significantly as a function of number of cues. Note that a prioritybased explanation of these results would not be valid, because this type of explanation describes the initiation of attentional operations (i.e., the sequence in which they are invoked). More specifically, the priority-tagging account would predict that the probability of a target's ap- 
pearing at the currently attended cued location (as opposed to an unattended cued location) would decrease as the number of cues increased. And therefore, the magnitude of the cue effect should decrease as a function of the number of cues presented. Instead, the equivalence of the cue effect on two-, three-, and four-cue trials suggests that although a single direct cue will capture attention, competition between multiple simultaneous direct cues appears to prevent any one of them from capturing attention (although the sensory activity caused by their onsets results in nonattentional processing facilitation). ${ }^{1}$

Note that although arguments can be made for associating the processing facilitation observed under multiple direct-cue conditions with sensory operations (see Wright \& Richard, 2003), we will use the more theoretically neutral term of nonattentional facilitation to refer to this effect in the remainder of this paper.

Whereas the study by Wright and Richard (2003) indicated that attentional capture did not occur on multiplecue trials, other visual search studies have indicated that multiple abrupt-onset stimuli do capture attention in a sequential manner (Yantis \& Johnson, 1990; Yantis \& Jones, 1991). ${ }^{2}$ One way to reconcile this difference may be to consider the strategic elements associated with each task. In the visual search experiments, subjects are usually required to determine whether or not one of the several stimuli appearing in a particular display is the target. Finding the target, therefore, usually involves attending to each of several display items in turn until the target is found. In contrast, the subjects in Wright and Richard's (2003) multiple-cue experiment were more likely to adopt a strategy that did not involve attending to any particular abrupt-onset cue, because on each trial, the single target was equally likely to appear at any of the cued locations (the subjects had to respond only as soon as the unambiguous target appeared at any location). Therefore, there was no strategic advantage to shifting attention to a particular cued location prior to the target's onset. So perhaps the extent to which a stimulus will capture attention is greater when the optimal response strategy involves explicitly attending to the particular locations of multiple abrupt-onset stimuli than when the optimal response strategy involves not explicitly attending to any location.

If strategic factors influence stimulus-driven attention shifts to direct cues, perhaps stimulus-driven attentional capture can be modulated by top-down goals. This is consistent with claims that abrupt-onset stimuli may or may not capture attention, depending on the observer's strategic attentional control setting (Folk, Remington, \& Johnston, 1992; Folk, Remington, \& Wright, 1994; however, see Theeuwes, 1992; Yantis, 1993). In particular, if a control setting is adopted that involves looking for a target whose location is defined by an abrupt onset, other abrupt-onset stimuli also capture attention. But if observers adopt a control setting for which the target is defined by some other stimulus aspect (e.g., a specific feature), an abrupt onset does not seem to capture attention, whereas stimuli with properties relevant to the atten- tional control setting do capture attention (e.g., Folk et al., 1992). Other models of how top-down processes may influence the bottom-up control of attentional allocation have also been developed to account for visual search results (e.g., Wolfe, 1994).

The purpose of the present experiments was to investigate the effects of multiple-cue presentations on the control of attention. One issue we examined was the topdown modulation of attentional capture. In particular, if it is assumed that top-down goals can influence attentional capture by multiple cues, then by manipulating the subjects' response strategies in the present experiments, it should be possible to produce attentional capture results like those obtained in visual search studies (e.g., Yantis \& Jones, 1991) while using the type of multiplecue displays that did not produce attentional capture results in our previous study (Wright \& Richard, 2003). Another issue we examined was the notion that the nonattentional processing triggered by the onset of the direct cues in the display may be sufficient to facilitate responses to targets independently of focused visual attention.

\section{EXPERIMENT 1}

The purpose of the first experiment was to determine whether or not attention can be captured by at least one of the multiple direct cues, using the same display as the one that did not produce attentional capture in a previous study (Wright \& Richard, 2003). To do so, we modified the task so that the subjects' optimal strategy involved attending to one of the cued locations. That is, one of the cues in the display (the unique cue) was altered so that it differed in color from the three other direct cues (the standard cues). In addition, the unique cue was highly predictive of the target onset location, so that the most efficient response strategy would involve attending to the unique-cue location. The target appeared at the uniquecue location on two thirds of the trials, at one of the standard cue locations on one sixth of the trials, and at an empty (uncued) location on one sixth of the trials. We reasoned that if the higher validity of the unique cue was sufficient to invoke goal-driven modulation of attentional capture at its location, cue effects should be significantly larger at the unique-cue location. We refer to the difference in cue effect magnitudes between uniquecue and standard-cue trials as the unique-cue advantage.

A secondary goal of this experiment was to provide further support for the claim that abrupt onsets can facilitate responses to targets independently of the attentional focus. If true, cue effects would also be expected at standard-cue locations but would be smaller than the attention-related cue effects at unique-cue locations.

Two different displays were used to control for any potential color-specific effects. In one display, the unique cue was red, and the standard cues were gray. In the second display, the colors were reversed, so that the unique cue was gray and the standard cues were red. All other aspects of the displays were identical. 


\section{Method}

Subjects. Twenty-six Simon Fraser University students were given course credit for taking part in the experiment. They were assigned to one of two groups of 13 and participated in a single testing session involving one of the two displays. All the subjects had normal or corrected-to-normal vision.

Apparatus. A microcomputer (PC) controlled the experiment timing and stimulus presentation. The stimuli were displayed on a 14-in. color monitor, and response times were recorded with a button box interfaced with a dedicated timing board in the computer. The subjects were tested in a dimly lit room in order to minimize reflections, and an adjustable chinrest was used to maintain head position at a distance of approximately $60 \mathrm{~cm}$ from the computer monitor.

Stimuli. All the stimuli were presented on a black (unlit) background $\left(0.07 \mathrm{~cd} / \mathrm{m}^{2}\right)$. A light-gray fixation cross $\left(0.4^{\circ} \times 0.4^{\circ}\right)$ remained visible in the center of the display throughout the experiment. In one display condition, the unique cue was a red bar $\left(0.8^{\circ} \times\right.$ $0.2^{\circ} ; 14.1 \mathrm{~cd} / \mathrm{m}^{2}$ ), and the standard cues were light-gray bars $\left(14.4 \mathrm{~cd} / \mathrm{m}^{2}\right)$ with the same dimensions. In the other display condition, the unique-cue and the standard-cue colors were reversed. The target was a white line $\left(1.1^{\circ} \times 0.1^{\circ} ; 55.5 \mathrm{~cd} / \mathrm{m}^{2}\right)$ tilted either to the left (on $50 \%$ of the trials) or to the right (on $50 \%$ of the trials) at a $45^{\circ}$ angle. ${ }^{3}$ The target was easy to detect under these conditions, thereby reducing the likelihood that the subjects would execute an eye movement to the target before responding. There were eight possible cue and target positions arranged in a circle around the fixation cross (see Figure 1). The midpoints of all the cue locations were $6.2^{\circ}$ from the center of the fixation cross and $5.5^{\circ}$ from the midpoints of adjacent cue locations. The target appeared just above a cue location, so that cues and targets did not overlap if both occurred at the same position.

Procedure. The subjects were instructed to direct their eyes toward the fixation cross throughout the experiment and to press the response button as quickly as possible when they detected the target's appearance. They were also told the probabilities of the target's appearing at the unique-cue, standard-cue, and uncued locations on any given trial.

Each trial began with a 1.5 - to 2 -sec intertrial interval. Following this, the unique cue and three standard cues appeared at randomly selected display locations and remained visible for the duration of the trial (see Figure 1). After the 100-msec CTOA, the target appeared at one of the eight possible locations and remained visible until the subject responded. Response times were measured as the interval between the target onset and the buttonpress. All the cues and targets were extinguished following the subject's response, which marked the end of the trial.

The testing session was divided into several blocks of approximately 50 trials. The first block was used for practice, and the data from this block were not analyzed. One quarter of the trials in each block were catch trials, in which the target appeared at a 1,500-msec CTOA. These trials were randomly interspersed among the data trials. Catch trial responses were collected but not analyzed, because their sole purpose was to minimize response anticipation errors.

Design. The main variable of interest in this experiment was target location, which was the location at which the target appeared in the display on a given trial; the unique-cue location, one of the standardcue locations, or an uncued location. Unique-cue trials occurred most often $(66.7 \%$ of the trials). Standard-cue and uncued trials were equally likely to occur ( $16.7 \%$ of the trials). Thus, the 720 data trials consisted of 480 unique-cue, 120 standard-cue, and 120 uncued trials. In addition, the 240 catch trials (1,500-msec CTOA) had the same 4:1:1 ratio of unique:standard:uncued trials.

Data analysis. Before any statistical analyses were carried out, response times less than $100 \mathrm{msec}$ and greater than $1,000 \mathrm{msec}$ were excluded from the analysis as errors. Following this, response times greater than three standard deviations from the corresponding trial type means were also removed. Analyses of variance (ANOVAs) were conducted with the errors in each experiment to determine

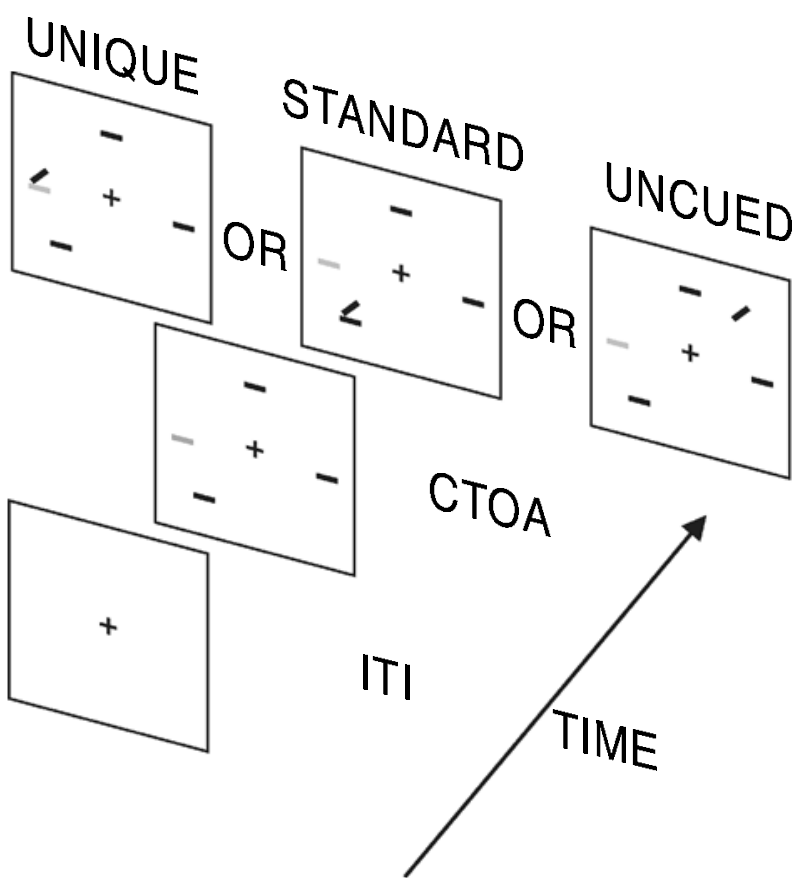

Figure 1. Example of basic stimulus display used in the uniquecue paradigm. The fixation cross is visible for the intertrial interval (ITI), and then the cues precede the target by the cue-target onset asynchrony (CTOA). Finally, the target appears at the unique-cue, a standard-cue, or an uncued location.

whether or not speed-accuracy tradeoffs occurred. These analyses are not reported, because no significant speed-accuracy tradeoffs were found.

The statistical analyses performed on the remaining data were repeated measures ANOVAs. Huynh-Feldt-corrected degrees of freedom were used to determine probability values for all factors with more than two levels, to compensate for any violation of the assumption of sphericity. Specific hypotheses were tested with planned comparisons, using the Bonferroni inequality to control the family-wise error rate (set at 0.15 ). The same analysis procedure was used in all the experiments.

\section{Results and Discussion}

The data from each display condition were analyzed separately, because the standard-cue effects differed in the two cases. The mean error rate was $1.8 \%$ in Display Condition 1 and 2.2\% in Display Condition 2. Table 2 lists mean response times in the two display conditions, averaged across all the subjects. A one-way repeated measures ANOVA was conducted with the pooled mean response times for all the subjects for each level of the target location factor (unique cue, standard cue, or uncued) for each display condition. The main effect of target location was significant for each type of display $\left[F(2,24)=120.675, M S_{\mathrm{e}}=37.543, p<.001\right.$, for Display 1 , and $F(2,24)=41.924, M S_{\mathrm{e}}=104.370, p<.001$, for Display 2]. Pairwise comparisons are presented in brackets in Table 2.

The unique-cue advantage was significant in both display conditions. This indicates that the presentation of a 
Table 2

Mean Response Times and Cue Effects (in Milliseconds) as a Function of Target Location for the Two Different Displays Used in Experiment 1 (With $p$ Values for Planned Comparisons)

\begin{tabular}{|c|c|c|c|c|c|}
\hline \multirow{2}{*}{$\begin{array}{c}\text { Target } \\
\text { Location }\end{array}$} & \multirow{2}{*}{$\begin{array}{c}\text { Mean } \\
\text { Response Time }\end{array}$} & \multicolumn{2}{|c|}{ Cue Effect } & \multirow{2}{*}{$\begin{array}{c}\text { Unique-Cue } \\
\text { Advantage }\end{array}$} & \multirow[b]{2}{*}{$p$} \\
\hline & & $M$ & $p$ & & \\
\hline \multicolumn{6}{|c|}{ Display 1 (Red Unique Cue) } \\
\hline Unique cue & 334 & 35 & $<.001$ & 8 & $<.001$ \\
\hline Standard cue & 342 & 27 & $<.001$ & - & _- \\
\hline Uncued & 369 & - & - & - & - \\
\hline \multicolumn{6}{|c|}{ Display 2 (Gray Unique Cue) } \\
\hline Unique cue & 340 & 37 & $<.001$ & 18 & $<.001$ \\
\hline Standard cue & 358 & 19 & .005 & - & - \\
\hline Uncued & 377 & - & - & - & - \\
\hline
\end{tabular}

high-validity unique cue can draw attention to its location in a stimulus-driven manner. This effect is unlikely to have arisen solely from the goal-driven orienting processes associated with symbolic-cuing experiments, because the facilitation under those conditions is typically minimal, with CTOAs as short as $100 \mathrm{msec}$ (e.g., Müller $\&$ Findlay, 1988). In addition, the occurrence of attentional capture at the unique-cue location indicated by the uniquecue advantage also suggests that the primarily bottom-up capture process can be influenced by an observer's strategic goals (see Folk et al., 1992). Another notable finding is that significant cue effects occurred on standard-cue trials. This result is consistent with the claim that the appearance of abrupt-onset stimuli triggers nonattentional processing that can facilitate target detection responses independently of attentional processes.

\section{EXPERIMENT 2}

Before making strong claims about the results of the first experiment, we conducted additional tests to control for some display-specific properties that may have affected the results. In particular, the magnitude of the standard-cue effects in the first experiment differed across display conditions. One possible explanation of this difference is that, in one of the display conditions more so than in the other, the effective luminance (brightness) of the unique cue, relative to that of the standard cues, may have been greater. This seemed unlikely, because the same combination of colors was used in both displays. In order to rule out this explanation, however, we conducted Experiment $2 \mathrm{~A}$ to replicate the first experiment while equating the brightness of the standard and the unique cues. In addition, the unique cue in Experiment $2 \mathrm{~A}$ was green instead of red. This color change was intended to increase the effectiveness of brightness matching, because the visual system is less sensitive to light in the "red" part of the visible-light spectrum (e.g., Hallett, 1963).

Another modification of the first experiment was a change in the target in Experiment 2A from a tilted line to a small box. This was intended to control for the possibility that the target in Experiment 1 (tilted line) may have combined with the nearby cue on unique- or standardcue trials to form an emergent object (an angle shape). In particular, if emergent objects were somehow easier to detect than the target alone, response times may have been shorter on cued trials than on uncued trials, in which no emergent object was present. Visual inspection suggested that the box target did not readily combine with the cue to form a new perceptual object.

Experiment 2B was a further attempt to replicate Experiment 1 , using a target identification task rather than a target detection task. This was meant to ensure that Experiment 1 addressed general attention-orienting processes that are common to both detection and identification.

\section{Experiment 2A}

\section{Method}

Subjects. Fifteen University of British Columbia students were paid $\$ 5$ for participating in a $1-\mathrm{h}$ testing session. All the subjects had normal or corrected-to-normal vision.

Apparatus and Stimuli. The apparatus and stimuli were the same as those in Experiment 1, except for the following changes: (1) Only one type of display was used, and it contained a green unique cue accompanied by three gray standard cues; (2) brightness of the unique (green) cue was matched with the brightness of the standard (gray) cues; and (3) the target was a small box $\left(0.2^{\circ} \times\right.$ $0.2^{\circ}$ ) rather than a diagonal line.

Brightness matching. Brightness matching was carried out using a variation of the flicker photometry technique. The subjects viewed gray and green patches $\left(20^{\circ} \times 20^{\circ}\right)$ that alternated in the center of the screen at a frequency of $60 \mathrm{~Hz}$. The luminance of the gray patch remained constant while the subjects adjusted the luminance of the green patch. A method of limits procedure with ascending and descending stimulus series was used to find the luminance level for the green patch that produced the least flicker. The final luminance for each subject was calculated as the average of four runs (two alternating ascending and descending runs).

Procedure and Design. The procedure and design were similar to those in Experiment 1, with the exception that the subjects were also instructed to focus their attention on the unique cue when it appeared. In addition, they were told that they could earn extra money for doing this consistently throughout the experiment. Focusing on the unique cue was demonstrated to the subjects by having them fixate on the central cross and then "notice" or attend to the unique cue in their visual periphery. Pilot study results indicated that this behavioral control minimized differences in the strategic approaches that individual subjects employed during an experimental session. 


\section{Results and Discussion}

The mean error rate in this experiment was $1.8 \%$. A one-way repeated measures ANOVA was conducted with the pooled mean response times for all the subjects for each level of the target location factor (unique cue, standard cue, or uncued). Table 3 lists the mean response times, averaged across all the subjects, and the mean cue effects. The main effect of target location was significant $\left[F(2,28)=40.02, M S_{\mathrm{e}}=153.89, p<.001\right]$. Significant cue effects occurred for both types of cues, which accounts for the main effect of target location. Furthermore, cue effects were significantly larger on unique-cue trials than on standard-cue trials, resulting in a unique-cue advantage. These data replicate the basic finding of Experiment 1 and suggest that the results of the latter were not due to differences in brightness of the cues or to differences in configural properties of cue-target combinations.

\section{Experiment 2B}

\section{Method}

Subjects. Twelve University of British Columbia students were paid $\$ 5$ for participating in a $1-\mathrm{h}$ testing session. All the subjects had normal or corrected-to-normal vision.

Procedure and Design. The procedure and design were similar to those in Experiment 1, except for the following changes: (1) The subjects were instructed to press a button with their left hand if the top of the target was tilted to the left $(\backslash)$ and to press another button with their right hand if the top of the target was tilted to the right (/); (2) the subjects were instructed to focus their attention on the unique cue, as in Experiment 2A; and (3) only one type of display was used (red unique cue and gray standard cues).

\section{Results and Discussion}

The mean error rate in this experiment was $3.2 \%$. A one-way repeated measures ANOVA was conducted with the pooled mean response times for all the subjects for each level of the target location factor (unique cue, standard cue, or uncued). Table 3 lists the mean response times, averaged across all the subjects, and the mean cue effects. The main effect of target location was significant $\left[F(2,22)=24.60, M S_{\mathrm{e}}=274.82, p<.001\right]$. Significant cue effects occurred for both types of cues, which accounts for the main effect of target location. Furthermore, cue effects were significantly larger on unique-cue trials than on standard-cue trials, resulting in a uniquecue advantage. These data provide a clear replication of Experiment 1 with a target identification task.

\section{Experiment 2C}

The results of the previous experiments are consistent with the notion that standard-cue effects are involuntarily triggered by the abrupt onset of the standard cues. An alternative possibility, however, is that the subjects responded to targets that appeared at standard-cue locations faster than to targets at uncued locations because the cues reduced the uncertainty about where the target could appear in the display (see Luck, Hillyard, Mouloua, \& Hawkins, 1996).

The purpose of Experiment $2 \mathrm{C}$ was to show that it was the abrupt onset of the standard cues, and not reduced location uncertainty, that was necessary for producing standard-cue effects. This was done by using a display procedure in which the cues appeared at locations previously occupied by placeholders (see Yantis \& Jonides, 1984). The placeholders were identical to the standard cues, so the onset of the cue display involved the offset of the placeholders at the uncued locations and, at the unique-cue location, the placeholder's becoming red. Note that the resulting cue display was basically identical to the one used in the previous experiments.

If reduced location uncertainty alone was sufficient to produce standard-cue effects, cue effects similar to those observed in the previous experiments should occur at the standard-cue locations, since the cue display was the same. In contrast, if it was the abrupt onset of the standard cues that was critical, standard-cue effects should be eliminated, because the cues no longer had abrupt onsets.

\section{Method}

Subjects. Fourteen Simon Fraser University students were given course credit for participating in a 1-h testing session. All the subjects had normal or corrected-to-normal vision.

Table 3

Mean Response Times and Cue Effects (in Milliseconds) as a Function of Target Location in Experiments 2A, 2B, and 2C (With $p$ Values for Planned Comparisons)

\begin{tabular}{|c|c|c|c|c|c|}
\hline \multirow{2}{*}{$\begin{array}{c}\text { Target } \\
\text { Location } \\
\end{array}$} & \multirow{2}{*}{$\begin{array}{c}\text { Mean } \\
\text { Response Time }\end{array}$} & \multicolumn{2}{|c|}{ Cue Effect } & \multirow{2}{*}{$\begin{array}{l}\text { Unique-Cue } \\
\text { Advantage }\end{array}$} & \multirow[b]{2}{*}{$p$} \\
\hline & & $M$ & $p$ & & \\
\hline \multicolumn{6}{|c|}{ Experiment $2 \mathrm{~A}$} \\
\hline Unique cue & 348 & 40 & $<.001$ & 23 & $<.001$ \\
\hline Standard cue & 371 & 17 & $<.001$ & - & - \\
\hline Uncued & 388 & - & - & - & - \\
\hline \multicolumn{6}{|c|}{ Experiment $2 \mathrm{~B}$} \\
\hline Unique cue & 473 & 46 & $<.001$ & 13 & .007 \\
\hline Standard cue & 486 & 33 & .003 & - & - \\
\hline Uncued & 519 & - & - & - & - \\
\hline \multicolumn{6}{|c|}{ Experiment $2 \mathrm{C}$} \\
\hline Unique cue & 347 & 26 & $<.001$ & 31 & $<.001$ \\
\hline Standard cue & 377 & -4 & .325 & - & - \\
\hline Uncued & 373 & - & - & - & - \\
\hline
\end{tabular}


Procedure and Design. The procedure and design were similar to those in Experiment 1, except for the following changes. First, at the beginning of the trial (1.5-2 sec before the cues were displayed), placeholders appeared at all display locations. The placeholders were identical in shape, color, and luminance to the gray standard cues. Second, the presentation of the cue display involved the removal of the placeholders at the uncued locations, in addition to the placeholder's becoming red at the unique-cue location. No changes occurred to the placeholders/cues occupying the standard-cue locations. The CTOA on all the data trials was $100 \mathrm{msec}$.

\section{Results and Discussion}

The mean error rate in this experiment was $1.1 \%$. A one-way repeated measures ANOVA was conducted with the pooled mean response times for all the subjects for each level of the target location factor (unique cue, standard cue, or uncued). Table 3 lists the mean response times, averaged across all the subjects, and the mean cue effects. The main effect of target location was significant $\left[F(2,26)=33.75, M S_{\mathrm{e}}=3,875.05, p<.001\right]$. As is indicated by Table 3 , cue effects were significant only for unique-cue trials.

The absence of standard-cue effects suggests that the present results are inconsistent with the notion that the reduction in location uncertainty associated with the cued locations was responsible for the standard-cue effects and, instead, suggests that the abrupt onset of standard cues was necessary. These data are consistent with the results of previous studies, which have shown that a reduction of location uncertainty is not necessary to produce cue effects (e.g., Luck et al., 1996).

These results also confirm the conclusion from Experiment $2 \mathrm{~A}$ that cue effects do not arise solely because the cue-target configuration (an angle shape) that occurs at cue locations is somehow more readily detectable than the target alone, because the cue-target configuration in the present experiment, which was identical to the one used in the previous experiments, did not produce cue effects.

Another notable finding was that significant cue effects still occurred on unique-cue trials, although they were somewhat diminished in comparison with uniquecue magnitudes in most of the other experiments. This suggests that other processes besides the abrupt onset of the cue are involved in generating these cue effects.

\section{EXPERIMENT 3}

The results of the first two experiments indicate that attention was captured at the unique-cue location and that cue effects also occurred when targets were presented at the standard-cue locations. This result could be considered to be consistent with the priority-tagging model in the following way: If high validity caused unique cues to consistently capture attention with a higher priority than did the standard cues (see Wolfe, 1994), perhaps subjects' attentional allocation was characteristic of a serial search for the target. ${ }^{4}$ More specifically, the first location attended to could be the uniquecue location (highest priority signal), followed by the standard-cue locations (high-priority signals) and then, finally, any uncued locations (low-/null-priority signals). This would produce response times that were shortest for unique-cue trials, longest for uncued trials, and somewhere in between for standard-cue trials, which is exactly the pattern observed in the previous experiments.

The purpose of Experiment 3 was to determine whether a serial search explanation provides a viable account of the cue effect pattern observed in the previous experiments. This was done by varying the number of standard cues presented on a trial. According to the serial search explanation, there should be an interaction between response times on unique-cue trials and response times on standard-cue and uncued trials. More specifically, because the unique-cue location is said to be attended to first, the number of cues should not affect response times on these trials. However, in the other cue conditions, increasing the number of cues would affect the number of standard-cue and uncued locations that had to be attended to before the target was found. Consequently, response times on these trials should increase as a function of the number of standard cues presented in the display. In contrast, the nonattentional facilitation account predicts that varying the number of cues would have no effect on standard-cue response times. This prediction is based on the claim that nonattentional processing is triggered in parallel by each abrupt-onset stimulus and, therefore, the facilitation that results from such activity would be the same for stimuli at all cued locations, regardless of their number.

\section{Method}

Subjects. Fourteen University of British Columbia students were paid $\$ 10$ for participating in two 1-h testing sessions. All the subjects had normal or corrected-to-normal vision.

Procedure. The procedure was the same as that in Experiment 1, except that the unique cue appeared with one, two, or three standard cues and only one type of display was used (red unique cue and gray standard cues). In addition, the subjects were given the same attentional focus instructions as those in Experiment 2A.

Design. The number of standard cues (one, two, or three) variable was crossed with the target location variable. The 1,296 data trials consisted of 288 unique-cue, 72 standard-cue, and 72 uncued trials for each level of the number of standard cues factor. Also, 432 catch trials (1,500-msec CTOA) had the same 4:1:1 ratio of unique: standard:uncued trials.

\section{Results and Discussion}

The mean error rate in this experiment was $2.4 \%$. A $3 \times 3$ repeated measures ANOVA was conducted with the pooled mean response times for all the subjects in each condition. The within-subjects factors were number of standard cues (one, two, or three) and target location (unique cue, standard cue, or uncued). Figure 2 shows the mean response times averaged across all the subjects. Although the main effect of target location $\left[F(2,26)=10.22, M S_{\mathrm{e}}=2,964.01, p<.01\right]$ was significant, neither the main effect of number of standard cues $\left[F(2,26)=1.35, M S_{\mathrm{e}}=72.09, p=.27\right]$ nor the number of standard cues $\times$ target location interaction $[F(4,52)=$ $\left.0.071, M S_{\mathrm{e}}=187.77, p=.99\right]$ was significant. 
EXPERIMENT 3: MEAN RESPONSE TIMES

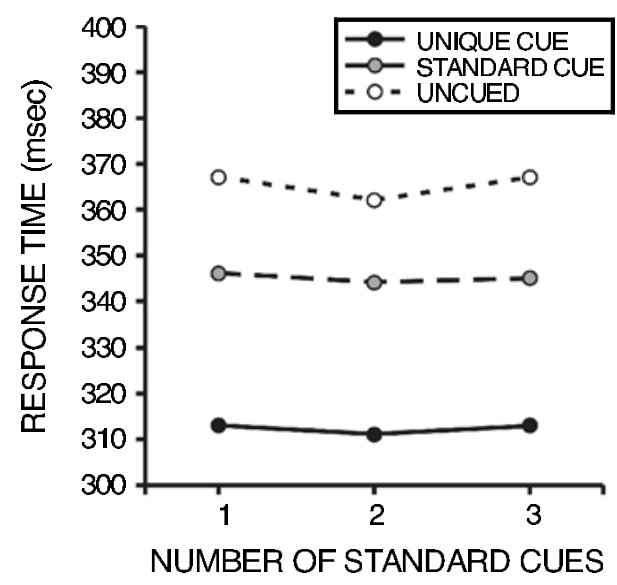

EXPERIMENT 3: CUE EFFECTS

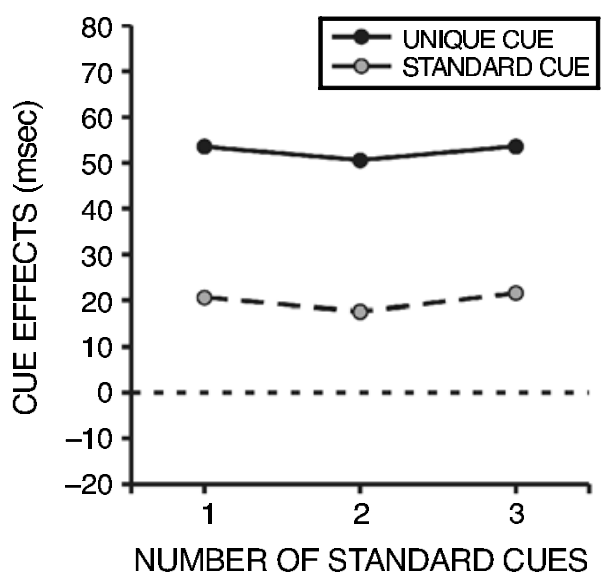

Figure 2. Mean response times and mean cue effects as a function of the number of standard cues in Experiment 3.

The mean cue effects are presented in Table 4 and in Figure 2. Significant cue effects occurred on both uniquecue and standard-cue trials, which accounts for the main effect of target location. Further inspection reveals that cue effects were not changed by manipulations of the number of standard cues variable, which indicates that this factor did not affect target detection responses on standard-cue trials. This is confirmed by the absence of a number of standard cues $\times$ target location interaction. The failure to find this interaction suggests that standardcue effects do not occur merely as a by-product of the sequential allocation of attention to the various display positions on the basis of their priority or usefulness but, rather, seem to arise from nonattentional operations that occur in parallel at all standard-cue locations.

These data are also relevant to the issue of reduced location uncertainty as an explanation for standard-cue effects. In particular, changing the number of standard cues in the present experiment would have affected the degree of location uncertainty associated with each display condition. The finding that these changes in location uncertainty were not mirrored by corresponding changes in cue effect magnitudes across the number of standard cues suggests that location uncertainty is not a factor in standard-cue effects, which is consistent with the results of Experiment 2C.

Table 4

Mean Cue Effects as a Function of Number of Standard Cues in Experiment 3 (With $p$ Values for Planned Comparisons)

\begin{tabular}{|c|c|c|c|c|c|c|}
\hline \multirow[b]{3}{*}{ Cue } & \multicolumn{6}{|c|}{ Number of Standard Cues } \\
\hline & \multicolumn{2}{|c|}{1} & \multicolumn{2}{|c|}{2} & \multicolumn{2}{|c|}{3} \\
\hline & $M$ & $p$ & $M$ & $p$ & $M$ & $p$ \\
\hline Unique & 54 & .004 & 51 & .001 & 54 & .004 \\
\hline Standard & 21 & .001 & 18 & .016 & 22 & .011 \\
\hline
\end{tabular}

\section{EXPERIMENT 4}

One conclusion that could be drawn from the previous experiments is that stimulus-driven attentional capture can be modulated by goal-driven processes. More specifically, we have suggested that attentional capture by unique cues may be due to a goal-driven response strategy adopted by subjects after assessing cue validities. There is, however, an alternative explanation of how unique cues may capture attention. Perhaps they do so simply because their red color is a unique feature (see Wolfe, 1994). The results of several visual search studies indicate that attention can be guided in a stimulusdriven manner by the relative saliency of the items in a display, where saliency corresponds approximately to how unique an item is relative to the other items in the display (e.g., Theeuwes, 1991a, 1992; Todd \& Kramer, 1994; Wolfe, Cave, \& Franzel, 1989; however, see Chastain \& Cheal, 1998; Folk \& Annett, 1994). Moreover, this saliency-based control of attention occurs even if salient items are no more likely to be the target than are the other items in the display. Thus, it is worth asking whether or not, in the previous experiments, the unique cue captured attention simply because it was the only red item in a display with gray items.

One way to test this question is to eliminate the topdown incentive to explicitly attend to the unique cue by adjusting its validity so that targets are no more likely to appear at unique-cue locations than they are to appear at any other display location on a given trial. This is what we did in Experiment 4. According to the saliency-based view of attentional capture, this change should have no effect on the unique-cue advantage, because unique cues should still capture attention by virtue of their unique color. On the other hand, if goal-driven processes modulate attentional capture in a display of multiple direct 
cues, removing the incentive to attend to the unique cue should reduce the occurrence of attentional capture at the unique-cue location. Instead, unique-cue effects should have the same magnitude as standard-cue effects, because only stimulus-driven processes associated with nonattentional facilitation would affect target detection response times. Thus, in this experiment, we removed the top-down incentive to attend to the unique cue by adjusting cue validities so that the targets were equally likely to appear at any of the locations within the stimulus display.

\section{Method}

Thirteen Simon Fraser University students were given course credit for participating in the experiment. The apparatus and stimuli were identical to those in Experiment 1, except that only one type of display was used (red unique cue and gray standard cues). The procedure and design were also the same as those in Experiment 1, except that unique-cue, standard-cue, and uncued trials occurred with different frequencies. More specifically, the target appeared at the unique-cue location on $12.5 \%$ of the trials, at a standard-cue location on $37.5 \%$ of the trials ( $12.5 \%$ at each standard-cue location), and at ancued location on $50 \%$ of the trials $(12.5 \%$ at each uncued location). The 768 data trials consisted of 96 unique-cue, 288 standard-cue, and 384 uncued trials. The 256 catch trials $(1,500-\mathrm{msec}$ CTOA) had the same 1:3:4 ratio of unique:standard:uncued trials. The subjects were told that the target was equally likely to appear at any of the cued or uncued locations in the display.

\section{Results and Discussion}

The mean error rate in this experiment was $1.6 \%$. A one-way repeated measures ANOVA was conducted with the pooled mean response times for all the subjects for each level of the target location factor (unique cue, standard cue, or uncued). Table 5 lists the mean response times and cue effects, averaged across all the subjects. The main effect of target location was significant $[F(2,24)=$ $\left.14.06, M S_{\mathrm{e}}=74.491, p<.001\right]$. Although significant cue effects occurred on both types of cued trials, however, the unique-cue advantage was completely eliminated. This suggests that the unique cue will not capture attention in the absence of an incentive to attend to it (see also Chastain \& Cheal, 1998). Moreover, the similar and significant magnitudes of cue effects on standard-cue and unique-cue trials are consistent with the notion that nonattentional processing of the cues facilitated target detection responses.

The absence of attentional capture based solely on the unique cue's color is not consistent with the results of some visual search studies (Theeuwes, 1991a, 1992). This inconsistency might be explained by again considering the strategic requirements of each type of task. As was discussed previously, the optimal strategy in visual search tasks involves attending to display items because each is a possible target, whereas the optimal strategy in the multiple-cue task in this experiment most likely involves not explicitly attending to any one of the direct cues. ${ }^{5}$

\section{EXPERIMENT 5}

The results of Experiment 4 suggest that attentional capture does not occur when subjects view a multiple-cue display but do not have an incentive to attend to one of the cued locations. This indicates that attentional capture is mediated, in part, by the strategy that observers adopt to perform a task.

The purpose of the present experiment was to provide further evidence for the notion that response strategy is critical in determining whether or not attentional capture occurs in a multiple-cue display. One way to do this is to use the same procedure as the one that did not produce attentional capture in Experiment 4 but to modify the task requirements so that they induce the subjects to attend to the unique-cue location. This was done in the present experiment by including a secondary task in which the subjects determined the position of a briefly presented gap $(50 \mathrm{msec})$ that appeared on one side of the unique cue. The gap was not easily visible and required attentional processing for successful localization (in a pilot study in which the gap was present on the unique cue but subjects were not required to perform the gap localization task, the subjects reported being completely unaware of the gap). We predicted that this requirement to attend to the unique-cue location would yield attentional capture even in absence of the high cue validity that was necessary to produce attentional capture in the previous experiments.

In addition to the secondary task, other changes were made to the unique-cue procedure, to control for possible confounds. First, to control for the chance that the onset or removal of the gap might somehow affect attention orienting, gaps were also embedded in the standard cues. Second, to provide a more sensitive measure of attention orienting, a second (200 msec) CTOA was added, in case the subjects required more time to attend to the unique-cue location with this procedure. In all other respects, the design of this experiment was the same as that in Experiment 4.

Table 5

Mean Response Times and Cue Effects as a Function of Target Location in Experiment 4 (With $p$ Values for Planned Comparisons)

\begin{tabular}{lcccccc}
\hline \multirow{2}{*}{$\begin{array}{c}\text { Target } \\
\text { Location }\end{array}$} & $\begin{array}{c}\text { Mean } \\
\text { Response Time }\end{array}$ & \multicolumn{2}{c}{ Cue Effect } & & Unique-Cue \\
\cline { 3 - 5 } Advantage & & $p$ \\
\hline Unique cue & 350 & 18 & .002 & & 2 & .140 \\
Standard cue & 352 & 16 & .001 & - & - & - \\
Uncued & 368 & - & - & & & - \\
\hline
\end{tabular}


We reasoned that if the response strategy determines the occurrence of attentional capture in a multiple-cue display, inducing subjects to attend to the unique-cue locations with an attention-demanding task should produce a unique-cue advantage.

\section{Method}

Subjects. Fifteen University of British Columbia undergraduates were paid $\$ 5$ for participating in a $1-\mathrm{h}$ session. All the subjects had normal or corrected-to-normal vision.

Stimuli and Procedure. All the cues were identical to those in Experiment 1, except that each cue appeared with a gap $\left(0.2^{\circ} \times\right.$ $0.2^{\circ}$ ) located randomly inside either the right or the left edge of the cue. The gap was a complete break in the continuity of the cue's form and was visible only for $50 \mathrm{msec}$, after which it was "filled in."

Cuing task. The cuing task was identical to that in Experiment 1, except that the subjects were given a financial incentive to perform the gap task as accurately as possible and to respond to the target as quickly as possible (pilot studies indicated that it was necessary to give incentives for good performance of both the target detection and the gap localization tasks). The CTOA on data trials was $100 \mathrm{msec}$ on one half of the trials and $200 \mathrm{msec}$ on the other half of the trials in each block.

Gap task. On $25 \%$ of the trials, after responding to the target, the subjects saw a display screen with a query about the position of the gap on the "red" cue. This query occurred on only $25 \%$ of the trials, because pilot studies indicated that subjects tended to sacrifice target detection task performance if asked more frequently. They indicated the position of the gap by pressing a button. Responses were not timed, and the subjects were instructed to guess if they were unsure about the gap position. The next trial began after the gap response was made. The subjects were given feedback about their accuracy at the end of each block.

Practice session. Before beginning the experiment, the subjects were given practice with the gap task. The practice session was identical to a test session, except that no targets were presented and the gap position was queried on each trial. The subjects completed blocks of 50 trials until (1) their accuracy in the gap task for a block exceeded $80 \%$ and (2) they indicated that they felt comfortable with the task. Two subjects were not able to perform to these standards and were excused from further participation.
Design. The CTOA variable (100 or $200 \mathrm{msec}$ ) was crossed with the target location variable. Unique-cue validity was $12.5 \%$, standardcue validity was $37.5 \%$, and uncued validity was $50 \%$, meaning that the target was equally likely to appear at any of the display locations on a given trial. In total, there were 576 data trials consisting of 72 unique-cue, 216 standard-cue, and 288 uncued trials for each level of CTOA. The 300 catch trials $(1,500-\mathrm{msec}$ CTOA) also had the same 1:3:4 trial ratio.

\section{Results and Discussion}

Trials in which the subjects made an incorrect response on the gap task (7.1\% of all the data trials) were included in the analysis. The main reason for this was that most of the subjects reported that many of their errors occurred because they forgot the position of the gap by the time they had to respond to this task. Moreover, removing these trials had virtually no effect on mean response times, so they were left in to increase the number of observations per condition. It should be noted that including trials in which the subjects did not attend to the unique-cue location and, consequently, would be unable to perform the gap task would reduce cue effects on unique-cue trials.

The mean error rate in this experiment was $5.7 \%$. A $2 \times 3$ repeated measures ANOVA was conducted with the pooled mean response times for all the subjects in each condition. The within-subjects factors were CTOA (100 or $200 \mathrm{msec}$ ) and target location (unique cue, standard cue, or uncued). Figure 3 shows the mean response times averaged over all the subjects. The main effects of both CTOA $\left[F(1,14)=83.95, M S_{\mathrm{e}}=653.91, p<.001\right]$ and target location $\left[F(2,28)=12.47, M S_{\mathrm{e}}=415.46, p<\right.$ $.001]$ were significant. The CTOA $\times$ target location interaction, however, was not significant $\left[F(2,28)=2.99, M S_{\mathrm{e}}=\right.$ 216.80, $p=.067]$.

Mean response times are presented in Figure 3, and mean cue effects are presented in Table 6 . As is indicated

\section{EXPERIMENT 5: MEAN RESPONSE TIMES}

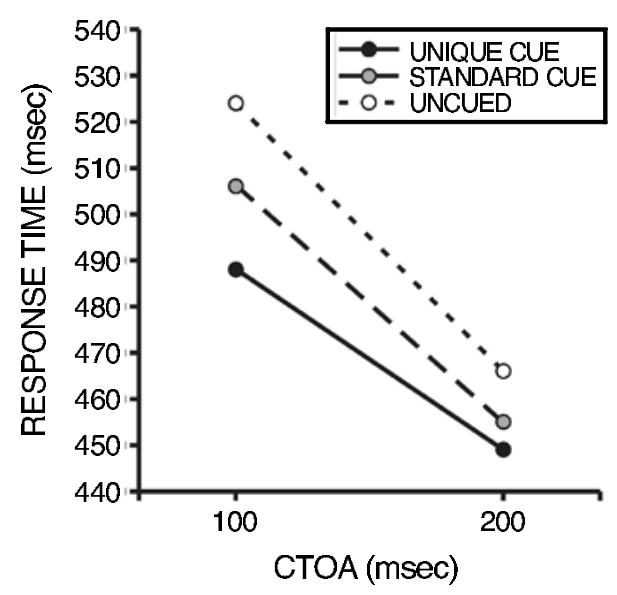

\section{EXPERIMENT 5: CUE EFFECTS}

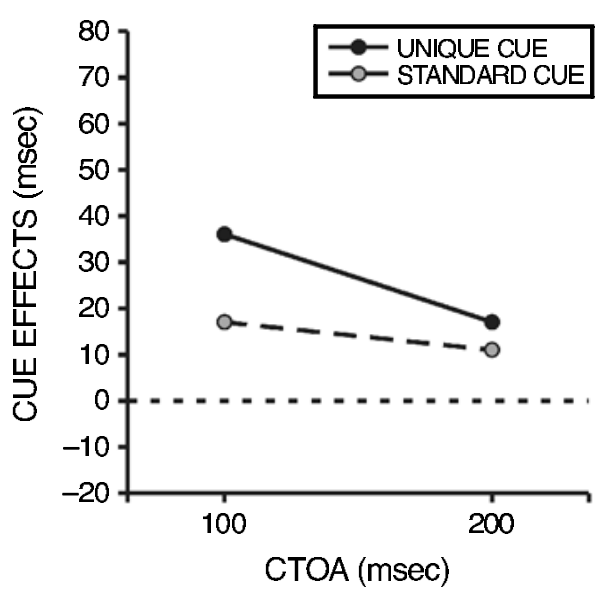

Figure 3. Mean response times and mean cue effects as a function of cue-target onset asynchrony (CTOA) in Experiment 5. 
in Figure 3, the significant effect of CTOA seems to arise from generally shorter response times on 200-msec CTOA trials, which is probably due to an enhanced alerting effect at that CTOA. In addition, the main effect of target location appears to arise from shorter response times on unique-cue and standard-cue trials than on uncued trials (see Figure 3).

On the most relevant CTOA trials $(100 \mathrm{msec})$, the cue effect pattern closely resembled the unique-cue effect pattern found in the other experiments. More important for the present hypothesis, the unique-cue advantage was significant even though the subjects were given neither specific instructions nor a cue validity incentive to attend to that location. The unique-cue advantage must, therefore, be attributed to the attention-demanding secondary task that the subjects performed at the uniquecue location.

Note also that standard-cue effects occurred in this experiment as well. This is consistent with the idea that direct cues can generate nonattentionalfacilitation. Although not central to the purpose of this experiment, the cue effects on 200-msec CTOA trials were smaller on both uniquecue and standard-cue trials. This decrease in unique-cue effects probably occurred because the subjects had completed the gap task and were no longer required to focus attention at the unique-cue location. In addition, the decrease in standard-cue effects is probably a reflection of the transient nature of direct-cue effects (e.g., Nakayama \& Mackeben, 1989).

\section{EXPERIMENT 6}

The results of the previous experiments indicate that two different processes may be involved in generating cue effects at the unique-cue location. The first process seems to be attentional and to occur when observers have some incentive to attend to this location. The second process seems to be nonattentional and to occur in parallel at multiple cued locations, even in the absence of any incentive to attend to a particular location within the display. The purpose of Experiment 6 was find further evidence for the claim that the processes mediating unique-cue and standard-cue effects operate independently.

One method to test this independence is to determine how each process operates across time (CTOA). The results of previous studies indicate that cue effects generated by high-validity direct cues, which are similar to the

Table 6

Mean Cue Effects as a Function of Cue-Target Onset Asynchrony (CTOA) in Experiment 5 (With $p$ Values for Planned Comparisons)

\begin{tabular}{|c|c|c|c|c|}
\hline \multirow[b]{3}{*}{ Cue } & \multicolumn{4}{|c|}{ CTOA (msec) } \\
\hline & \multicolumn{2}{|c|}{100} & \multicolumn{2}{|c|}{200} \\
\hline & $M$ & $p$ & $M$ & $p$ \\
\hline Unique & 36 & $<.001$ & 18 & .012 \\
\hline Standard & 17 & .025 & 11 & .044 \\
\hline Unique-cue advantage & 19 & .035 & 7 & .350 \\
\hline
\end{tabular}

unique cue, are sustained over time (e.g., Cheal \& Lyon, 1991). In contrast, cue effects generated by multiple lowvalidity direct cues, which are similar to the standard cues, are transient and become attenuated at CTOAs greater than $100 \mathrm{msec}$ (Wright \& Richard, 2003). Thus, if separate processes were involved in generating cue effects in the previous experiments, manipulating CTOA in a similar experiment may cause cue effects to be sustained at unique-cue locations but to be transient at standard-cue locations. This type of dissociation would indicate that unique-cue and standard-cue effects are mediated by separate processes that operate differently over time.

The CTOAs used in the present experiment ranged from $100 \mathrm{msec}$ (optimal for stimulus-driven cue effects) to $400 \mathrm{msec}$ (optimal for goal-driven cue effects).

\section{Method}

Subjects. Fifteen University of British Columbia students were paid $\$ 10$ for participating in two 1-h testing sessions. All the subjects had normal or corrected-to-normal vision.

Procedure. The procedure was the same as that in Experiment 1, except that CTOAs on data trials were 100, 200, 300, or $400 \mathrm{msec}$. In addition, only one type of display was used (red unique cue and gray standard cues), and the subjects were given instructions to focus their attention on the unique cue while holding their eyes fixated on the central fixation cross, as in Experiment 2A.

Because the present experiment used somewhat longer CTOAs, although still in the usual range of facilitative cue effects, the possibility exists that the subjects may have made eye movements on some of the trials and that this may have contributed significantly to the observed cue effects. There are two arguments that this possibility is unlikely in the present case. The first argument is that the stimuli were designed so that the experimental tasks could be performed easily without the need to foveate or look directly at the stimuli. Cues and targets were fairly bright and were located relatively near to (about $6^{\circ}$ from) the central fixation cross, in a perifoveal location. It is routine to eschew monitoring eye movements under these conditions unless there is some additional incentive for subjects to move their eyes. For example, in a thorough study of practice effects in inhibition of return, using similar stimuli, Pratt and McAuliffe (1999) did not monitor eye movements in any of their three experiments, even for CTOAs of over $1 \mathrm{sec}$. The second argument is that we have measured eye movements in other, very similar experiments with both short and long CTOAs, which yielded the same basic pattern of results (means are presented in the Discussion section), and found that eye movements occurred on fewer than $1 \%$ of the trials (Richard, 1999). Moreover, the low eye movement rates occurred even though these other experiments involved factors that should have maximized the incentive to execute eye movements (e.g., $80 \%$ unique-cue validity, target identification task, and long CTOAs).

Design. The target location variable was completely crossed with the CTOA variable $(100,200,300$, or $400 \mathrm{msec})$. On each trial, the target appeared at the unique-cue location $(66.7 \%$ of the trials), one of the standard-cue locations ( $16.7 \%$ of the trials), or one of the uncued locations ( $16.7 \%$ of the trials). The 1,800 data trials consisted of 300 unique-cue, 75 standard-cue, and 75 uncued trials for each level of CTOA. In addition, 600 catch trials (1,500-msec CTOA) had the same 4:1:1 ratio of unique:standard:uncued trials.

\section{Results and Discussion}

The mean error rate in this experiment was $1.7 \%$. A $4 \times 3$ repeated measures ANOVA was conducted with the pooled mean response times for all the subjects in 
each condition. The within-subjects factors were CTOA $(100,200,300$, or $400 \mathrm{msec})$ and target location (unique cue, standard cue, or uncued). Figure 4 shows the mean response times averaged across all the subjects. The main effects of CTOA $\left[F(3,42)=30.88, M S_{\mathrm{e}}=508.64\right.$, $p<.01]$ and target location $\left[F(2,28)=16.69, M S_{\mathrm{e}}=\right.$ $1,810.79, p<.01]$ and the CTOA $\times$ target location interaction $\left[F(6,84)=6.76, M S_{\mathrm{e}}=86.75, p<.01\right]$ were all significant. Mean cue effects are presented in Table 7 and in Figure 4.

In the 100-msec CTOA condition, the cue effect pattern was a replication of the basic pattern observed in the other experiments in this study. At longer CTOAs, however, a different pattern emerged. Cue effect magnitudes remained at their high levels on unique-cue trials, which is consistent with the results of other studies showing that goal-driven direct-cue effects can occur rapidly and be sustained over time (e.g., Cheal \& Lyon, 1991). In contrast, on standard-cue trials, cue effect magnitudes became attenuated after $100 \mathrm{msec}$, which is consistent with the results of other multiple direct-cue studies that indicate that these effects are transient (Wright \& Richard, 2003). This result provides strong evidence that different processes may mediate cue effects at the unique-cue and standard-cue locations.

The pattern of cue effects also suggests that eye movements were not a factor in this experiment. If eye movement were a consistent part of the subject's strategy, uniquecue effects should have shown a stepwise change at longer CTOAs in which eye movements were possible, as compared with trials involving shorter CTOAs, in which the possibility of eye movements was precluded by the short interval between the cue and the target onsets (e.g., Fischer \& Weber, 1993). This claim is also consistent with the results of another, similar study in which eye movements were monitored (Richard, 1999). In this case, a nearly identical display condition yielded unique-cue and standard-cue effects of $49 \mathrm{msec}(p=.002)$ and $21 \mathrm{msec}$ $(p<.001)$, respectively, in the $100-\mathrm{msec}$ CTOA condition and $52 \mathrm{msec}(p=.002)$ and $2 \mathrm{msec}(p=.837)$ in the 400 -msec CTOA condition. This pattern occurred despite the fact that eye movements were observed on fewer than $1 \%$ of the trials.

The present results also indicate that there is an interaction between attentional and nonattentional processing of unique cues. Other researchers have investigated the possibility of just such an interaction by presenting a high-validity symbolic cue in the same display as one with a single low-validity direct cue (Riggio \& Kirsner, 1997). Comparisons of response times on trials in which both types of cues indicated the same location versus trials in which they indicated different locations suggested that goal-driven and stimulus-driven cue effects were purely additive and, therefore, may have occurred at different stages of visual processing (see Sternberg, 1969).

The data from the present experiment, however, are not consistent with this view. More specifically, if the interaction were purely additive, unique-cue effects should have changed to reflect corresponding decreases in standard-cue effects as CTOA was increased (although the overall magnitude of unique-cue effects should have remained high). But the observed data indicate that unique-cue effects did not change with CTOA. Another possibility is that a threshold process is involved in orienting attention (see LaBerge \& Brown, 1989; Wright \& Richard, 2003). In this case, stimulus-driven effects may interact with goal-driven effects to increase nonattentional effects at the cued location enough for it to surpass a threshold, thereby opening a channel of focused attention at the location in question (see Figure 4). Thus, additional stimulus-driven facilitation that increases activation beyond the threshold level may not af-
EXPERIMENT 6: MEAN RESPONSE TIMES

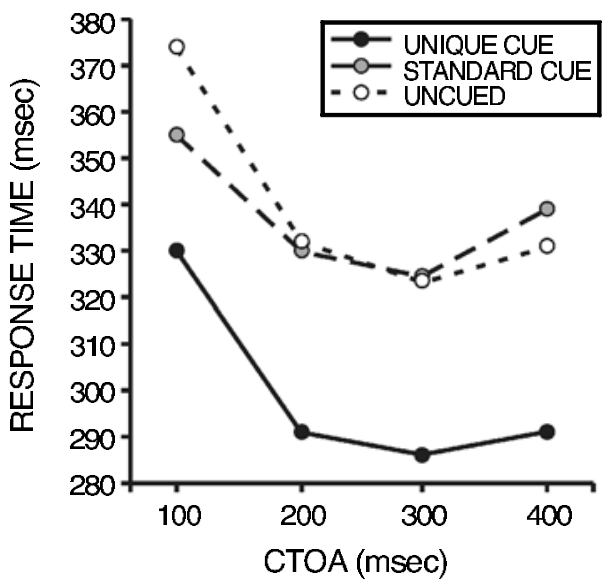

\section{EXPERIMENT 6: CUE EFFECTS}

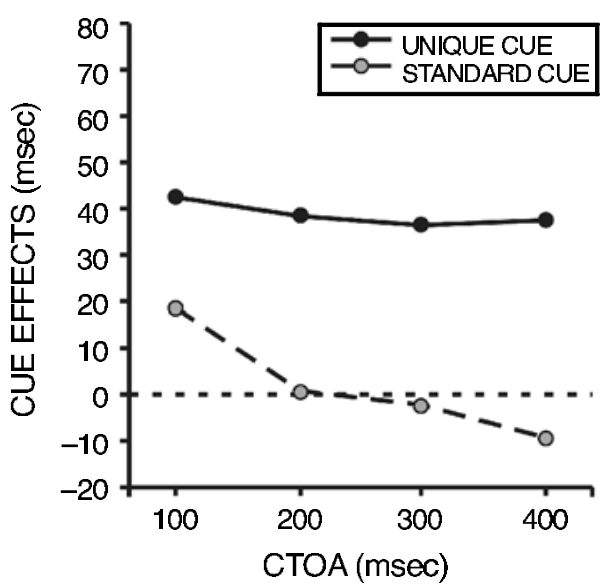

Figure 4. Mean response times and mean cue effects as a function of cue-target onset asynchrony (CTOA) in Experiment 6. 
Table 7

Mean Cue Effects as a Function of Cue-Target Onset Asynchrony (CTOA) in Experiment 6 (With $p$ Values for Planned Comparisons)

\begin{tabular}{|c|c|c|c|c|c|c|c|c|}
\hline \multirow[b]{3}{*}{ Cue } & \multicolumn{8}{|c|}{ CTOA (msec) } \\
\hline & \multicolumn{2}{|c|}{100} & \multicolumn{2}{|c|}{200} & \multicolumn{2}{|c|}{300} & \multicolumn{2}{|c|}{400} \\
\hline & $\bar{M}$ & $\bar{p}$ & $\bar{M}$ & $\bar{p}$ & $\bar{M}$ & $\bar{p}$ & $M$ & $\bar{p}$ \\
\hline$\overline{\text { Unique }}$ & 44 & .001 & 40 & .001 & 38 & .001 & 39 & $<.001$ \\
\hline Standard & 20 & $<.001$ & 2 & .654 & -1 & .905 & -8 & .096 \\
\hline
\end{tabular}

fect responses. Note that this proposal leaves open the possibility that stimulus-driven and goal-driven effects interact in an additive manner at subthreshold levels (see Riggio \& Kirsner, 1997).

\section{GENERAL DISCUSSION}

The experiments in this paper were conducted to investigate the control of visual attention in a multiple direct-cue paradigm. Two general conclusions can be drawn from this research. The first is that operations triggered by direct cues can facilitate processing in the absence of focused attention at direct-cue locations. The second is that attentional capture in a multiple-cue display can be contingent on the observer's top-down goals.

\section{Stimulus-Driven Facilitation}

Direct cues in this study triggered attention-independent processing that occurred in parallel at multiple locations and facilitated processing of targets appearing there. This claim is supported by the finding that significant standard-cue effects occurred in all the experiments, even when attention was captured at the unique-cue location. Furthermore, the data from Experiments 3 and 4 suggest that direct-cue effects occurred in parallel across the visual scene. Note that if only one of the standard cues had captured attention (see Yantis \& Jones, 1991) or if attention had been probabilistically allocated to the different cued locations (e.g., Shaw, 1984), cue effects should have varied as a function of the number of standard cues presented on a given trial. This was not the case. The results of Experiment 4 also indicated that the stimulus-driven cue effect magnitudes were the same at all the cued locations. In particular, the cue effects at the single low-validity unique-cue location were the same as the cue effects at the three different standard-cue locations. Finally, the results of Experiment 6 suggest that the effects initiated by the standard cues occurred independently of attentional processing, as indicated by the dissociation of unique- and standard-cue effects when CTOA was varied. Taken together, these findings provide converging support for the notion that direct cues can trigger location-specific operations that facilitate target processing independently of focused attention.

Other studies with similar procedures have also provided evidence that direct-cue effects may be a product of nonattentional operations (e.g., Riggio \& Kirsner, 1997; Tepin \& Dark, 1992). In these studies, a symbolic cue indicated a probable target onset at one location, and a direct cue indicated a probable target onset at another location. Target detection response times at both cued locations were facilitated relative to baseline. In contrast, another set of studies employing both symbolic and direct cues indicated that if the symbolic cue preceded an abrupt-onset stimulus by at least $200 \mathrm{msec}$, the effect of the latter's onset on target detection was suppressed (Theeuwes, 1991b; Yantis \& Jonides, 1990; however, see Chastain \& Cheal, 1997). The resulting claim was that the 200 -msec delay gave subjects enough time to engage their attention at the symbolic-cue location and that this had the effect of "blocking out" attentional capture by abrupt-onset events outside of the region of attentional focus. In the present experiments, the subjects were not given advance warning about the location of the unique cue, so they were not able to engage attention there to the same degree as in the experiments with the 200-msec warning, which could explain why the standard cues remained effective (Theeuwes, 1991b; Yantis \& Jonides, 1990).

Cue effects on standard-cue trials can be accounted for by nonattentional operations (Wright \& Richard, 2003). In particular, simultaneously presented multiple direct cues initiate location-specific processing, but competition may prevent activation at any single location from surpassing a criterion threshold required for capturing attention. Consequently, the only observable cue effects may arise from nonattentional processing (see Experiment 4). The present results suggest, however, that this activity may also be accessible to top-down processes. That is, top-down processes operating at the unique-cue location may cause activation there to exceed the activation at other locations by enough to surpass the threshold, resulting in the opening of an attention channel at that location (see Figure 4).

\section{Goal-Driven Attentional Capture}

The other major finding in this investigation is that attentional capture in a multiple direct-cue paradigm may be contingent on top-down goals. In particular, giving the subjects an incentive to attend to the unique cue by making it highly predictive of the target location or by employing a secondary task that required the subjects to attend to the unique cue produced cue effects at that location that were comparable to those found in other studies in which the results were interpreted as reflecting attentional capture (e.g., Eriksen \& Yeh, 1985). More important, however, is that when this incentive was re- 
moved, unique cues were no more effective than standard cues (Experiment 4). Thus, attentional capture by multiple abrupt-onset stimuli seems to depend on the observer's strategy for performing the task.

This finding adds to a growing set of data implicating top-down operations in the stimulus-driven control of attention (e.g., Bacon \& Egeth, 1994; Egeth, Virzi, \& Garbart, 1984; Folk et al., 1992; McDonald \& Ward, 1999; Pashler, 1988). At a general level, the effects of top-down goals on performance can be categorized in two different ways. The first involves strategic-level effects. These effects form mutually exclusive settings, or strategies, that can involve the selection of one among several possibly independent ways of responding to information. For example, the results of one visual search study indicate that, under certain conditions, subjects could perform a search either by letting their attention be captured by the most salient display items or by simply checking for the presence of a unique target feature (Bacon \& Egeth, 1994). These strategies do not involve the simple addition or exclusion of certain processes but, rather, entirely different methods for performing the task.

The second category of top-down effects involves more tactical-level influences. In this case, the same processing pathway, or stream, is involved, but the operations within that stream are subject to modification. One example of this is the Guided Search model (e.g., Wolfe, 1994). According to this model, attention is controlled in a stimulus-driven manner on the basis of the saliency or uniqueness of the items in the display, with the most salient items receiving priority access to attention. Moreover, top-down processes have the capability to affect this control of attention by boosting the saliency associated with certain stimulus features (e.g., the color red). Thus, if an observer expects a red target in a display of other unique nonred distractor items, that target can be made to capture attention by boosting the saliency associated with the color red (see Wolfe et al., 1990). Note that although the same basic operations are involved in the control of attention, top-down processing modifies the effectiveness of a subset of these operations. The effects studied in the present investigation seem to fall into the tactical-level category. In particular, the high uniquecue validity affected only a single aspect of responses (the capture of attention), and the remaining effects were unchanged by top-down intervention.

A tactical-level model may also be able to provide some insight into how attention was captured in the present experiments. It is possible that a mechanism similar to the one involved in boosting saliency in the Guided Search model is also involved in boosting activation at the unique-cue location past threshold. In particular, it may be possible that subjects invoke a strategy that involves increasing the level of activation associated with the unique cue's unique color (see Figure 4). The consequences of this tactical-level adjustment would determine whether or not the unique cue captured attention in a multiple-cue display.
One point of note is that attention may be directed to a location in the display by selecting a specific feature, rather than by selecting a specific location, the latter being the type of selection typically observed in spatial-cuing studies that measure goal-driven attention shifts (e.g., Posner et al., 1980). Note that this feature-based selection would not have the effect of improving the quality of the perception of a designated feature but, rather, would improve the probability that the locations at which that feature occurs would be attended to with a higher priority (e.g., Moore \& Egeth, 1998; Shih \& Sperling, 1996; Tsal \& Lavie, 1993). Feature-based selection has a temporal advantage over location-based selection that is particularly important in the present series of experiments. More specifically, it takes approximately $300 \mathrm{msec}$ for goal-driven processes to direct attention to a location (i.e., with a symbolic cue; e.g., Müller \& Rabbitt, 1989). This makes it unlikely that the unique cue is selected solely on the basis of its location, because attentional capture effects are at optimal levels after only $100 \mathrm{msec}$ (see, e.g., Experiment 6). In contrast, feature-based selection may operate more efficiently. One reason for this may be that strategic use of the red feature can be activated as a "standing order" before the items appear in the display (because the critical feature is always known; see, e.g., Pashler, 1988), whereas location information must be resolved "on the fly" only after the unique cue appears. In addition, some researchers have suggested that preattentive feature information is available before location information about an object (e.g., Treisman \& Gelade, 1980). These factors may allow the unique-cue location to be selected for attentional capture in a rapid manner.

In conclusion, the results from the present investigation suggest that direct-cue effects may be associated with two different processes: an attention-related process that can be modulated by goal-driven factors and a nonattentional process that occurs in parallel at multiple direct-cue locations and is minimally affected by these goal-driven factors.

\section{REFERENCES}

Bacon, W. F., \& Egeth, H. E. (1994). Overriding stimulus-driven attentional capture. Perception \& Psychophysics, 55, 485-496.

Chastain, G., \& Cheal, M. (1997). Facilitatory or inhibitory nontarget effects in the location-cuing paradigm. Consciousness \& Cognition, 6, 328-347.

Chastain, G., \& Cheal, M. (1998). Automatic versus directed attention with single-element and multiple-element precues. Visual Cognition, 5, 339-364.

Cheal, M., \& Lyon, D. R. (1991). Central and peripheral precuing of forced-choice discrimination. Quarterly Journal of Experimental Psychology, 43A, 859-880.

Egeth, H. E., Virzi, R. A., \& Garbart, H. (1984). Searching for conjunctively defined targets. Journal of Experimental Psychology: Human Perception \& Performance, 10, 32-39.

Egeth, H. E., \& Yantis, S. (1997). Visual attention: Control, representation, and time course. Annual Review of Psychology, 48, 269-297.

ERIKSEN, C. W., \& YEH, Y.-Y. (1985). Allocation of attention in the visual field. Journal of Experimental Psychology: Human Perception \& Performance, 11, 583-597. 
Fischer, B., \& Weber, H. (1993). Express saccades and visual attention. Behavioral \& Brain Sciences, 16, 553-610.

Folk, C. L., \& ANnetT, S. (1994). Do locally defined feature discontinuities capture attention? Perception \& Psychophysics, 56, 277 287.

Folk, C. L., Remington, R. W., \& Johnston, J. C. (1992). Involuntary covert orienting is contingent on attentional control settings. Journal of Experimental Psychology: Human Perception \& Performance, 18, 1030-1044.

Folk, C. L., Remington, R. W., \& Wright, J. H. (1994). The structure of attentional control: Contingent attentional capture by apparent motion, abrupt onset, and color. Journal of Experimental Psychology: Human Perception \& Performance, 20, 317-329.

Gottlob, L. R., Cheal, M., \& Lyon, D. R. (1999). Attention operating characteristics in a location-cuing task. Journal of General Psychology, 126, 271-287.

Hallett, P. E. (1963). Spatial summation. Vision Research, 3, 9-24. Heinze, H.-J., Luck, S. J., Münte, T. F., Gös, A., Mangun, G. R., \& Hillyard, S. A. (1994). Attention to adjacent and separate positions in space: An electrophysiological analysis. Perception \& Psychophysics, 56, 42-52.

JoNIDES, J. (1981). Voluntary versus automatic control over the mind's eye's movement. In J. B. Long \& A. D. Baddeley (Eds.), Attention and performance IX (pp. 187-203). Hillsdale, NJ: Erlbaum.

JoNIDES, J., \& YANTIS, S. (1988). Uniqueness of abrupt visual onset in capturing attention. Perception \& Psychophysics, 43, 346-354.

JoSEPH, J. S., \& OPTICAN, L. M. (1996). Involuntary attentional shifts due to orientation differences. Perception \& Psychophysics, 58, 651665.

KASTNER, S., \& Ungerleider,L. G. (2000). Mechanisms of visual attention in the human cortex. Annual Review of Neuroscience, 23, 315-341.

Kiefer, R. J., \& Siple, P. (1987). Spatial constraints on the voluntary control of attention across visual space. Canadian Journal of Psychology, 41, 474-489.

Kramer, A. F., \& HAHn, S. (1995). Splitting the beam: Distributions of attention over noncontiguous regions of the visual field. Psychological Science, 6, 381-385.

LaBerge, D., \& Brown, V. (1989). Theory of attentional operations in shape identification. Psychological Review, 96, 101-124.

Luck, S. J., Hillyard, S. A., Mouloua, M., \& Hawkins, H. L. (1996). Mechanisms of visual-spatial attention: Resource allocation or uncertainty reduction? Journal of Experimental Psychology: Human Perception \& Performance, 22, 725-737.

McCormick, P. A., \& KLeIN, R. (1990). The spatial distribution of attention during covert visual orienting. Acta Psychologica, 75, 225-242.

McDonald, J. J., \& WARD, L. M. (1999). Spatial relevance determines facilitatory and inhibitory effects of auditory covert spatial orienting. Journal of Experimental Psychology: Human Perception \& Performance, 25, 1234-1252.

Moore, C. M., \& Egeth, H. (1998). How does feature-based attention affect visual processing? Journal of Experimental Psychology: Human Perception \& Performance, 24, 1296-1310.

Müller, H. J., \& Findlay, J. M. (1988). The effect of visual attention on peripheral discrimination thresholds in single and multiple element displays. Acta Psychologica, 69, 129-155.

Müller, H. J., \& RAbBitT, P. M. A. (1989). Reflexive and voluntary orienting of visual attention: Time course of activation and resistance to interruption. Journal of Experimental Psychology: Human Perception \& Performance, 15, 315-330.

Nakayama, K., \& Mackeben, M. (1989). Sustained and transient components of focal visual attention. Vision Research, 11, 1631-1647.

PASHler, H. (1988). Cross-dimensional interaction and texture segregation. Perception \& Psychophysics, 43, 307-318.

PoSNER, M. I. (1980). Orienting of attention. Quarterly Journal of Experimental Psychology, 32, 3-25.

PoSNer, M. I., \& Cohen, Y. (1984). Components of visual attention. In H. Bouma \& D. G. Bouwhuis (Eds.), Attention and performance X: Control of languageprocesses (pp. 531-556). Hillsdale, NJ: Erlbaum.

Posner, M. I., Snyder, C. R. \& Davidson, B. J. (1980). Attention and the detection of signals. Journal of Experimental Psychology: General, 109, 160-174.

Pratt, J., \& McAuliffe, J. (1999). Examining the effect of practice on inhibition of return in static displays. Perception \& Psychophysics, 61, 756-765.

RICHARD, C. M. (1999). Goal-driven and stimulus-driven control of visual attention in a multiple-cue paradigm. Dissertation Abstracts International, 61 (01), 569B.

Riggio, L., \& KirSner, K. (1997). The relationship between central cues and peripheral cues in covert visual orientation. Perception \& Psychophysics, 59, 885-899.

SHAW, M. L. (1984). Division of attention among spatial locations: A fundamental difference between detection of letters and detection of luminance increments. In H. Bouma \& D. G. Bouwhuis (Eds.), Attention and performance $X$ : Control of language processes (pp. 109121). Hillsdale, NJ: Erlbaum.

Shit, S., \& Sperling, G. (1996). Is there feature-based attentional selection in visual search? Journal of Experimental Psychology: Human Perception \& Performance, 22, 758-779.

Sternberg, S. (1969). The discovery of processing stages: Extensions of Donder's method. Acta Psychologica, 30, 276-315.

Tassinari, G., Aglioti, S., Chelazzi, L., Peru, A., \& Berlucchi, G. (1994). Do peripheral non-informative cues induce early facilitation of target detection? Vision Research, 34, 179-189.

Tepin, M. B., \& Dark, V. J. (1992). Do abrupt-onset peripheral cues attract attention automatically? Quarterly Journal of Experimental Psychology, 45A, 111-132.

Theeuwes, J. (1991a). Cross-dimensional perceptual selectivity. Perception \& Psychophysics, 50, 184-193.

TheEUWES, J. (1991b). Exogenous and endogenous control of attention: The effect of visual onsets and offsets. Perception \& Psychophysics, 49, 83-90.

Theeuwes, J. (1992). Perceptual selectivity for color and form. Perception \& Psychophysics, 51, 599-606.

Theeuwes, J., Kramer, A. F., \& Atchley, P. (1998). Visual marking of old objects. Psychonomic Bulletin \& Review, 5, 130-134.

Todd, S., \& Kramer, A. F. (1994). Attentional misguidance in visual search. Perception \& Psychophysics, 56, 198-210.

Treisman, A., \& Gelade, G. (1980). A feature integration theory of attention. Cognitive Psychology, 12, 97-136.

TSAL, Y., \& LAVIE, N. (1993). Location dominance in attending to color and shape. Journal of Experimental Psychology: Human Perception \& Performance, 19, 131-139.

Watson, D. G., \& Humphreys, G. W. (1997). Visual marking: Prioritizing selection for new objects by top-down attentional inhibition of old objects. Psychological Review, 104, 90-122.

Weichselgartner,E., \& Sperling, G. (1987). Dynamics of automatic and controlled visual attention. Science, 238, 778-780.

Wolfe, J. M. (1994). Guided Search 2.0: A revised model of visual search. Psychonomic Bulletin \& Review, 1, 202-238.

Wolfe, J. M., Cave, K. R., \& Franzel, S. L. (1989). Guided search: An alternative to the feature integration model for visual search. Journal of Experimental Psychology: Human Perception \& Performance, 15, 419-433.

Wolfe, J. M., Yu, K. P., Stewart, M. I., Shorter, A. D., FriedmanHiLL, S. R., \& CAVE, K. R. (1990). Limitations on the parallel guidance of visual search: Color $\times$ color and orientation $\times$ orientation conjunctions. Journal of Experimental Psychology: Human Perception \& Performance, 16, 879-892.

Wright, R. D. (1994). Shifts of visual attention to multiple simultaneous location cues. Canadian Journal of Experimental Psychology, 48, 205-217.

Wright, R. D., \& RICHARD, C. M. (1998). Inhibition of return is not reflexive. In R. D. Wright (Ed.), Visual attention (pp. 330-347). New York: Oxford University Press.

Wright, R. D., \& RichaRD, C. M. (2000). Location cue validity affects inhibition of return of visual processing. Vision Research, 40, 23512358.

Wright, R. D., \& Richard, C. M. (2003). Sensory mediation of stimulusdriven attentional capture in multiple-cue displays. Perception \& Psychophysics, 65, 925-938.

Wright, R. D., \& WARD, L. M. (1998). The control of visual attention. In R. D. Wright (Ed.), Visual attention (pp. 132-186). New York: Oxford University Press.

YANTIS, S. (1993). Stimulus-driven attentional capture and attentional 
control settings. Journal of Experimental Psychology: Human Perception \& Performance, 19, 676-681.

YAnTis, S. (1998). Control of visual attention. In H. Pashler (Ed.), Attention (pp. 223-256). Hove, U.K.: Psychology Press.

Yantis, S., \& Johnson, D. N. (1990). Mechanisms of attentional priority. Journal of Experimental Psychology: Human Perception \& Performance, 16, 812-825.

YANTIS, S., \& Jones, E. (1991). Mechanisms of attentional selection: Temporally modulated priority tags. Perception \& Psychophysics, $\mathbf{5 0}$, 166-178.

YANTIS, S., \& JoNIDES, J. (1984). Abrupt visual onsets and selective attention: Evidence from visual search. Journal of Experimental Psychology: Human Perception \& Performance, 10, 601-621.

YANTIS, S., \& Jonides, J. (1990). Abrupt visual onsets and selective attention: Voluntary versus automatic allocation. Journal of Experimental Psychology: Human Perception \& Performance, 16, 121-134.

\section{NOTES}

1. Note that the sensory-based facilitation and the priority-tagging accounts are compatible with one another. It is possible that similar mechanisms are involved in both scenarios but that the actions of these mechanisms are related to the type of visual processing required to perform the task at hand.

2. It is worth noting that whereas we present the sensory facilitation model as an alternative to the priority-tagging model, these proposals are not mutually exclusive. It is possible that both types of processes may be available to affect performance but that they operate at different stages and according to specif ic computational goals. For example, one possibility is that sensory activity generated by abrupt onsets also initiates the tagging of a location or object, in addition to facilitating processing at that location (Wright \& Richard, 2003).

3. The target was left-/right-tilted in Experiment 1 so that the same target stimulus could be used in an identification task in Experiment 2B.

4. For this to work, it would have to be assumed that the target onset would generate a priority signal that was lower than the current priority signal of the standard cues. Otherwise, it would capture attention before the standard cues, and response times on these trials would not be shorter than those on uncued trials. This could be possible if the top-down processes that boost the priority of the unique cue also affect the priority of the standard cues in some way (perhaps because both types of stimuli share the same size and shape).

5. There is some evidence suggesting that stimulus-driven attentional capture can occur in spatial-cuing experiments under special conditions (Joseph \& Optican, 1996). In one study, attention seemed to be captured by a low-validity cue because it appeared as a unique item embedded in a densely packed texture of homogeneous background items. The factors that caused attentional capture in that experiment were unlikely to have an effect in the present experiment, because the background texture (provided by the standard cues in this case) was very sparse.

(Manuscript received March 26, 2001; revision accepted for publication March 18, 2003.) 